Kosala, H., Francis, M. and Sirimewan, D., 2021. Applicability of blockchain technology to manage financial issues in the Sri Lankan construction industry. In: Sandanayake, Y.G., Gunatilake, S. and Waidyasekara, K.G.A.S. (eds). Proceedings of the $9^{\text {th }}$ World Construction Symposium, 9-10 July 2021, Sri Lanka. [Online]. pp. 86-97. DOI: https://doi.org/10.31705/WCS.2021.8. Available from: https://ciobwcs.com/papers/

\title{
APPLICABILITY OF BLOCKCHAIN TECHNOLOGY TO MANAGE FINANCIAL ISSUES IN THE SRI LANKAN CONSTRUCTION INDUSTRY
}

\author{
Himal Kosala ${ }^{1}$, Mathusha Francis ${ }^{2}$ and Diani Sirimewan ${ }^{3}$
}

\begin{abstract}
The construction industry is one of the largest industries in any country, contributing significantly to economic growth. A range of researchers explained that the construction industry suffered from numerous issues where financial issues are more critical. Late payments, cash flow issues, and lack of security of the payment are some of them. Blockchain technology shows a potential use for managing financial activities. Therefore, this research tends to investigate the applicability of blockchain technology to manage financial issues in the Sri Lankan construction industry. A comprehensive literature survey was carried out to assess the concept of blockchain technology and identified financial issues in the construction industry. A qualitative expert opinion survey was conducted with eight construction experts who had knowledge of the blockchain technology, selected through purposive sampling to collect data in a Sri Lankan context. The collected data was analysed using the content analysis method. The findings of the expert interviews indicated that faster transactions would help to reduce late payments; removing third parties from the transaction will reduce the involvement of many parties in the transaction process; and trust, security, transparency will help to increase foreign investments. Further, the lack of knowledge in the area, legal and tax issues, low investment, and social issues will be the challenges in adopting blockchain technology to the construction industry. The research finally suggests the ways to overcome such challenges in terms of using pilot projects, government rules and regulation. Thus, the research proposes that use of blockchain technology could minimise a significant number of financial issues in the construction industry.
\end{abstract}

Keywords: Blockchain technology; Cryptocurrencies; Distributed ledger technology; Financial issues; The construction industry.

\section{INTRODUCTION}

The construction industry is one of the biggest industries in the world (Al -Momani, 2000). However, the productivity in the construction industry has not changed compared to the other industries (McKinsey, 2015). Many industries use information technology to improve their productivity (Fulford and Standing, 2014). Furthermore, the authors mention that adopting information technology can help increase productivity in the construction industry. Artificial intelligence, robotics, cloud technology, and the Internet

\footnotetext{
${ }^{1}$ Department of Building Economics, University of Moratuwa, Sri Lanka, himalkosala1 @ gmail.com

${ }^{2}$ Department of Building Economics, University of Moratuwa, Sri Lanka, mathushaf@uom.lk

${ }^{3}$ Department of Building Economics, University of Moratuwa, Sri Lanka, dianis@uom.lk
} 
of Things (IoT) are just a few technologies that can help to improve the productivity in the construction industry (Ghosh et al., 2018).

One of the critical factors in the efficiency of the construction industry is the successful management of financial resources (Gundes et al., 2019). The absence of proper financial management will lead to financial issues in projects (Mehta, 2018). Financial issues will lead to delay in construction, which would be a severe problem for all the parties to the contract (Abdul - Rahman et al., 2011). Late payments, cash flow issues (Hewavitharana et al., 2018), unstable financial background, client's poor financial and business management, difficulties in obtaining loans from financiers, inflation (Ahmed and Ahmed, 2016), difficulties in transactions from the international market are the most significant financial issues in the construction industry (Yoo, 2017). To reduce these issues, the construction industry needs a transparent and traceable payment system that has more control from the client's side and enhances the accountability for every participant (Ramachandra and Rotimi, 2015). As a solution to this need, blockchain technology has been introduced (Nordgren and Weckstrom, 2019).

Blockchain technology is used to distribute, encrypt and secure logging of digital transactions (Turk and Klinc, 2017) and it is the fundamental technology of bitcoin and other cryptocurrencies (Zheng et al., 2017). All transactions and digital actions that have been executed and shared among the parties increase transparency and trust while reducing scams (Watson and Hjelte, 2018). Furthermore, the author specified that it would speed up a wide variety of business processes by removing the need for intermediaries and other relevant paperwork. Blockchain technology is one of the revolutionary technologies that can change industries, business models and operating procedures such as payment settlement, accounting, administration, supply chain, customer relations, and funding systems (Igwe et al., 2020). Blockchain has numerous applications in different areas such as IoT, finance, business, management, health, and education (Holotescu, 2018). Therefore, the purpose of this research is to investigate the applicability of blockchain technology in the Sri Lankan construction industry to manage financial issues.

\section{LITERATURE SYNTHESIS}

\subsection{FinANCIAL ISSUES ASSOCIATED WITH THE CONSTRUCTION INDUSTRY}

According to Kubba (2010), cost overruns are regarded as a major construction issue in projects, and they are extremely common in large-scale construction projects. Azis et al. (2012), mentioned that major causes of cost overrun as financial difficulties faced by contractors, schedule delays, poor site management and supervision, cash flow, fluctuation of prices of materials, lack of contractor's experience, frequent design changes and incorrect time and cost estimates. Late payments are one of the issues that arise as a result of some of the key players in construction projects (Harris and McCaffer, 2003). According to Gundes et al. (2019), cash flow issues are caused because of poor planning and controlling cash inflow and outflow. According to Abdul - Rahman et al. (2011), the external factor of poor economic conditions such as currency and inflation rate would have a significant impact on the cash flow of the project, thus affecting the project's timely performance and causing financial market instability, which would result in the construction project's cash flow problems. In addition, a lack of financial resources is a major issue that affects the project's cash flow and leads to a delay in site possession, 
which causes delays in the project (Abdul - Rahman et al., 2006). According to De Silva (2020), one of the major causes of financial issues in Sri Lanka is that obtaining a loan from a bank takes a longer period of time, which affects both contractors and clients. Abdul - Rahman et al. (2011), mentioned changes in interest rates, inflation, and the foreign exchange rate are all causes of market issues. Table 1 illustrates the summary of financial issues and causes for the issues found in the literature.

Table 1: Main financial issues and causes

\begin{tabular}{ll}
\hline \multicolumn{1}{c}{ Main issue } & \multicolumn{1}{c}{ Causes for main issue } \\
\hline Payment issues & Poor financial management by the employer \\
& Withhold of payment by the client \\
& Contractor's invalid claim \\
& Delay in valuation, certification of interim payment by consultant \\
& The inaccuracy of valuation for work done \\
& Insufficient documentation and information for valuation \\
& Involvement of too many parties in the process of certification \\
& The heavy workload of the consultant to evaluate variations \\
& Too many projects handled by the contractor at the same time \\
& Contractor's unstable financial background \\
Cash flow issues & Unqualified contractors underbidding the project cost \\
& Lack of regular cash flow forecasting \\
& Poor credit arrangement with creditors and debtors \\
& Difficulties in getting a loan from financiers \\
Financial resources & Allocation of government budget not in place \\
issues & Increment of interest rate in repayment of the loan \\
Market issues & Increment of the foreign exchange rate and inflation \\
\end{tabular}

\subsection{BLOCKCHAIN TECHNOLOGY}

\subsubsection{Nature of the Blockchain Technology}

In 2008, Nakamoto introduced blockchain technology to the industry. This technology is a continuously expandable list of data records, called "block", which are linked together using cryptographic methods (Gururaj et al., 2020a). Cryptography is a subset of cryptology that describes the creation of methods for encrypting information so it cannot be understood by unauthorised parties (Hellwig et al., 2020a). The blockchain information records can take any form, representing a money transfer, ownership, a transaction, someone's identity, or an agreement between two parties (Nakamoto, 2009). Blockchain technology disrupts the existing status quo through the elimination of traditional intermediary agents (Lall, 2020). Cryptographic hashing, digital signatures, document time stamping, mining, consensus algorithms, commitment protocols, and smart contracts are all important components of blockchain technology (Persis, 2020). To store digital transactions, it uses a decentralised, distributed, and immutable ledger (Xu et al., 2019). A peer-to-peer network is used to manage databases, where all the nodes in a network are identical and major concerns in the types of network architecture (Nakamoto, 2009). Figure 1 demonstrates the process of the blockchain system. 


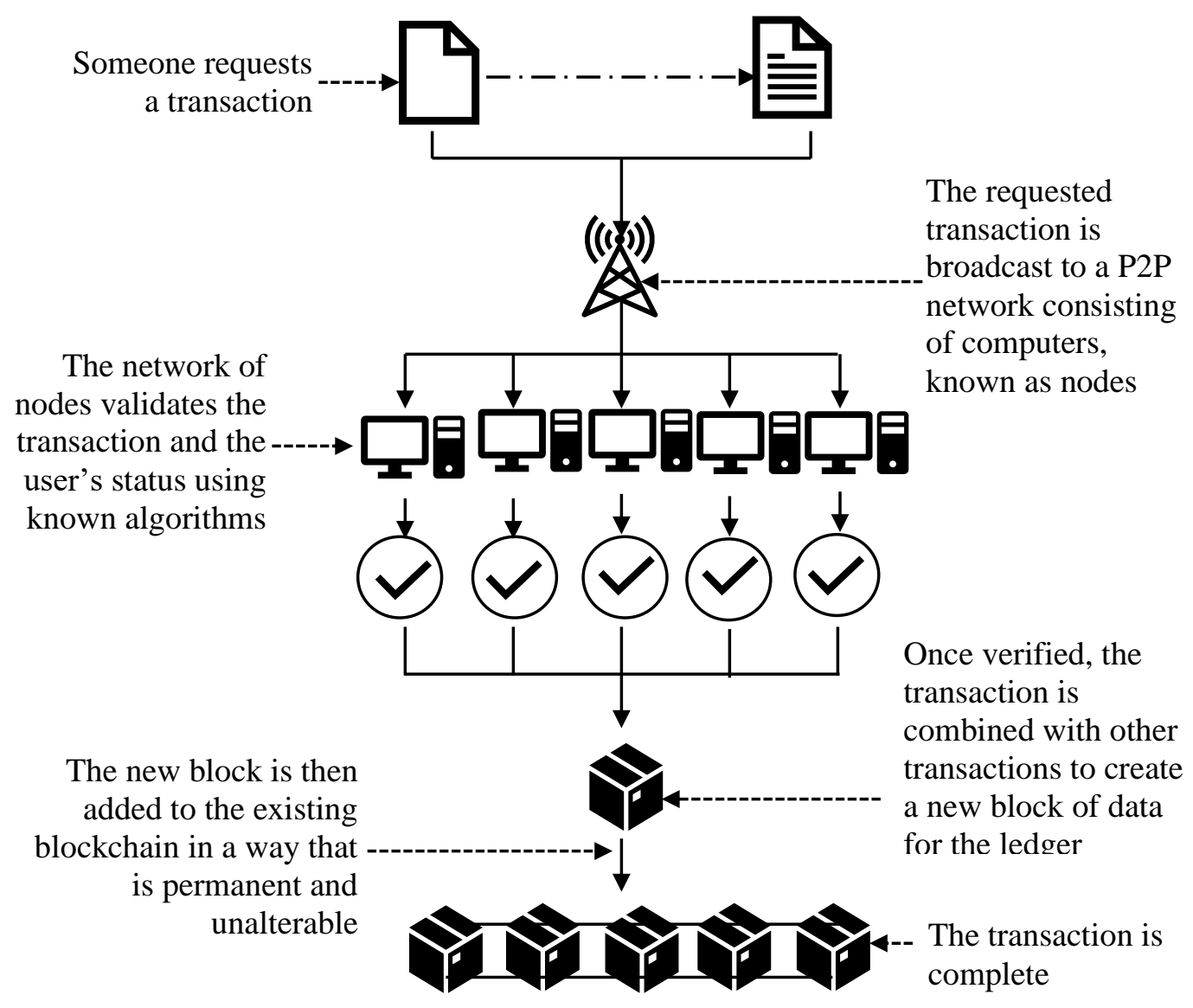

Figure 1: Process of the blockchain system (Source: Watson and Hjelte, 2018)

According to Figure 1, when one party requests a transaction, the information is broadcasted through a peer-to-peer network comprised of computers. These computers are referred to as nodes. The information in the transaction will then be verified by those nodes. Miners will create a block once that information has been verified. This block contains the transaction's hash, previous hash, and data. The request transaction will be completed once that new block is added to the chain.

\subsubsection{Cryptocurrencies}

When the world moves towards digital payments, and quick-payment transaction methods, information can easily be stored in a blockchain network (Gururaj et al., 2020b). Cryptocurrencies are used in peer-to-peer marketing to pay for and buy content in a secure manner (Nakamoto, 2009). Entries of units in a shared consensus-database called tokens or crypto-tokens make up the cryptocurrency fabric (Hellwig et al., 2020b). Because blockchain technology offers promising benefits such as transparency, accountability, integrity, immutability, and security, it has been linked to bitcoin, one of the most popular cryptocurrencies, and as a result, various fields are exploring and utilizing the benefits of blockchain technology (Persis, 2020). Bitcoin is the world's first virtual currency, which was introduced in 2008 (Nakamoto, 2009). Bitcoins are not real or tangible assets, and each bitcoin transaction is time-stamped by hashing it against the chain of existing blocks created using hash-based proof-of-work (Panda et al., 2020). 


\subsubsection{Distributed Ledger Technology}

Distributed Ledger Technology (DLT) is one of the most essential information technology innovations that can change organisations and associations in the economy, society, and industry (Sunyaev, 2020). The distributed network is a network architecture that distributes data, software, and computer programming across multiple nodes (computers), each of which is interdependent (Nakamoto, 2009). DLT is a broad term for technologies that use replicated, shared, and synchronised digital data between users of private or public distributed computer networks spread across multiple locations, geographies, or institutions (Ghaffari et al., 2020). The structure of blockchain is DLT, which provides the foundation for cryptocurrencies and a variety of other applications (Kuhn et al., 2019). One of the critical objectives of DLTs is to allow users who do not generally trust each other to communicate without having a trusted third party (Ioini and Pahl, 2018a). Furthermore, the authors mentioned that it provided a level of transparency, traceability, and security to the transaction. However, all DLTs are based on three wellknown technologies: public-key cryptography, distributed peer-to-peer networks, and consensus mechanisms, which have been combined in a unique and novel way (Ioini and Pahl, 2018b).

\section{METHODOLOGY}

The aim of this study was to investigate the applicability of blockchain technology to manage financial issues in the Sri Lankan construction industry. A comprehensive literature review was conducted by referring to journals, books, conference proceedings, and other reliable sources to assess the concept of blockchain technology and identify financial issues in the construction industry. Then, the current study adopts a qualitative research approach to investigate more financial issues in the industry as well as blockchain technology's applicability, benefits, challenges, and solutions for challenges in the Sri Lankan construction industry. Because there was a literature gap between the applicability, benefits, challenges, and solutions for challenges of blockchain technology in the Sri Lankan context.

A total of eight (08) experts are involved in the data collection using semi-structured interviews. The interviewees were chosen using a purposive sampling method from a pool of professionals with construction experience and knowledge of the blockchain concept. Among the eight participants, $50 \%$ are from the educational sector, $25 \%$ are from contractor organisations and the rest are from consultant organisations. In terms of experience, $80 \%$ of them have more than 10 years of experience in the construction industry. Amongst, four of them have vast knowledge in the construction industry and also have knowledge about new technologies. Also, all the educational sector interviewees have vast knowledge about blockchain technology. Because of that, the collected data from the experts was more reliable. To analyse the collected data, a content analysis was performed using NVivo 12 Pro. A summary profile of participants is presented in Table 2. 
Table 2: Profile of the participants

\begin{tabular}{|c|c|c|c|c|}
\hline Interviewee & $\begin{array}{c}\text { Type of } \\
\text { organisation }\end{array}$ & Designation & $\begin{array}{c}\text { Years of } \\
\text { experience }\end{array}$ & Key expertise areas \\
\hline IP1 & Consultant & Director & 15 Years & $\begin{array}{l}\text { Experience in different } \\
\text { financial issues, } \\
\text { Knowledge about new } \\
\text { technologies }\end{array}$ \\
\hline IP2 & Consultant & Director & 15 Years & $\begin{array}{l}\text { Experience in different } \\
\text { financial issues, } \\
\text { Knowledge about new } \\
\text { technologies }\end{array}$ \\
\hline IP3 & Contractor & Contract Manager & 14 Years & $\begin{array}{l}\text { Experience in different } \\
\text { financial issues, blockchain } \\
\text { technology }\end{array}$ \\
\hline IP4 & Contractor & AGM & 14 Years & $\begin{array}{l}\text { Experience in different } \\
\text { financial issues, } \\
\text { Knowledge about new } \\
\text { technologies }\end{array}$ \\
\hline IP5 & Educational & PhD Scholar & 5 Years & $\begin{array}{l}\text { Blockchain technology, } \\
\text { Carbon emission, Cost } \\
\text { management }\end{array}$ \\
\hline IP6 & Educational & $\begin{array}{l}\text { Doctoral } \\
\text { researcher }\end{array}$ & 13 Years & $\begin{array}{l}\text { Blockchain technology, } \\
\text { Software engineering, } \\
\text { Information system }\end{array}$ \\
\hline IP7 & Educational & Professor & 30 Years & $\begin{array}{l}\text { Blockchain technology, } \\
\text { Artificial intelligence, } \\
\text { Carbon emission, BIM }\end{array}$ \\
\hline IP8 & Educational & PhD Scholar & 5 Years & $\begin{array}{l}\text { Knowledge about } \\
\text { blockchain technology, } \\
\text { Offsite construction }\end{array}$ \\
\hline
\end{tabular}

\section{DATA ANALYSIS AND FINDINGS}

Since there is a lack of literature on proper investigations on blockchain applicability, benefits, challenges, and solutions for challenges in the Sri Lankan construction industry, expert interviews were conducted in order to identify additional financial issues as well as blockchain applicability, benefits, challenges, and solutions for challenges in the Sri Lankan context. As a result, semi-structured interviews were conducted with the goal of gathering expert opinions on the aforementioned topics. Later, using NVivo11, the opinions of interviewees were analysed, and the results of the analysis are presented in the following section.

\subsection{FinANCIAL ISSUES ASSOCIATED WITH THE CONSTRUCTION INDUSTRY}

In addition to Table1, the interviewees were asked to mention any financial issues and causes. IP-1 stated that non-payments and escalation issues are some of the major causes of construction projects, as well as exchange rates and bank debts for both clients and constructors. According to IP-2, some of the major causes are issues with employers' sources of funds, contractor poor performance, and material scarcity. Subcontractors' 
payment delays, problems obtaining bonds and guaranties from banks, lack of payment security, and bankruptcy are some of the causes of financial problems in the industry, according to IP-3 andIP-5. IP-4 stated that client financial arrangements, due to the different clauses in conditions of the contract, poor cash flow management, lack of creditability in suppliers and subcontractors, issues in payment terms, the difficulty of obtaining bank loans, and due to the economic downturn, will have major impact on financial issues. IP-6 stated that financial problems can arise as a result of quality issues and a lack of capital investment. According to IP-7, mistrust can have a significant impact on financial problems. IP-8 mentions that tax changes and interest claims impacted both the contractor's and client's financial arrangements. Figure 2 depicts the causes discovered through interviews.

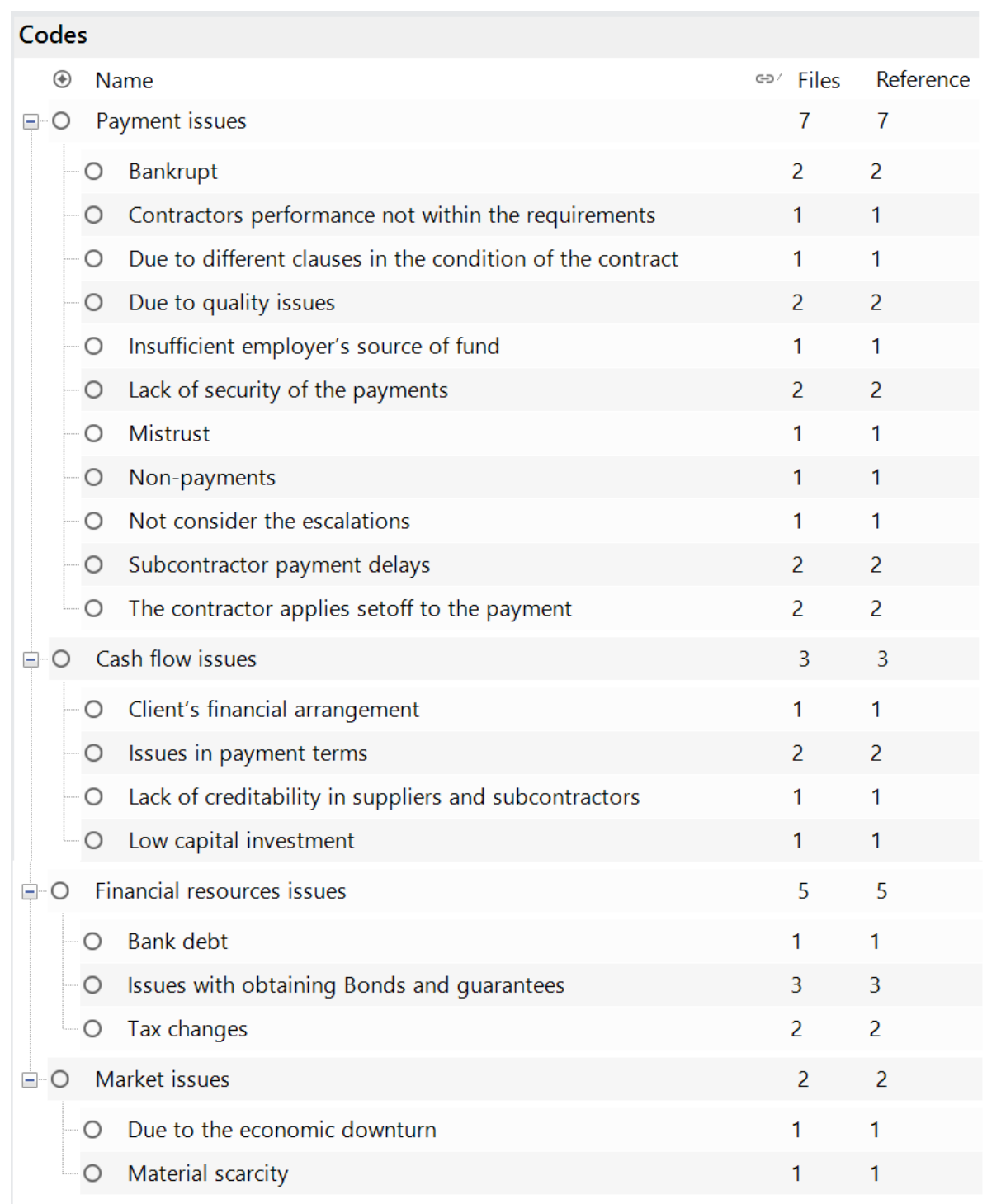

Figure 2: Causes discovered through the interviews

\subsection{BloCKCHAin TECHNOLOGY APPLiCABILITy, BENEFITS, CHALLENGES, AND SOlutions TO CHALlENGES}

In the interviews, participants were asked to indicate the applicability, benefits, challenges, and solutions for blockchain technology in the Sri Lankan construction 
industry. All of the experts agreed that blockchain technology has potential applications in the Sri Lankan construction industry. Furthermore, they outline the benefits of blockchain technology that can be obtained in the Sri Lankan context. Also stated the potential challenges that may arise as a result of technology and finally suggested how to overcome them.

\subsubsection{Benefits of Blockchain Technology}

Several benefits were found in the literature review and expert interviews. Figure 3 depicts the benefits of implementing blockchain technology in the Sri Lankan construction industry.

\begin{tabular}{|c|c|c|c|c|}
\hline \multicolumn{5}{|l|}{ Codes } \\
\hline \multirow[b]{2}{*}{$\boxminus 0$} & me & $\leftrightarrow$ & Files & References \\
\hline & nefits of the blockchain technology & & 7 & 7 \\
\hline $\mathrm{O}$ & Accountability & & 6 & 6 \\
\hline $\mathrm{O}$ & Auditability & & 3 & 3 \\
\hline $\mathrm{O}$ & Data immutability & & 3 & 3 \\
\hline 0 & Data responsibility & & 1 & 1 \\
\hline $\mathrm{O}$ & Decentralises transactions & & 3 & 3 \\
\hline 0 & Faster transactions & & 6 & 6 \\
\hline $\mathrm{O}$ & Security & & 3 & 3 \\
\hline-0 & Traceability & & 5 & 5 \\
\hline $\mathrm{O}$ & Transparency & & 5 & 5 \\
\hline $\mathrm{O}$ & Trust & & 5 & 5 \\
\hline
\end{tabular}

Figure 3: Benefits of blockchain technology

The main benefits, according to five out of eight experts, are traceability, accountability, transparency, fast transactions, and trust. Three of the five experts also mentioned that this technology can provide decentralised transactions, data immutability, security, and auditability. One out of them additionally mentioned that the responsibility of data and transaction will be provided by blockchain technology. Besides that, IP-2 stated that it will aid in the management of the industry's financial flow. According to IP-3, "normally, the transaction of the projects are huge values, interest rates, premium charges are also higher amounts because going for blockchain is very good for the industry". Traceability, accountability, transparency, fast transactions, decentralise transactions, digital payments, secure payments, auditability, trust, and responsibility of data and transaction are the benefits expert interviews. When compared to the Sri Lankan construction industry, experts agreed that using blockchain technology can deliver all of these benefits.

\subsubsection{Applicability of Blockchain Technology to Manage Financial Issues}

During the interviews, participants were asked to identify financial issues that can be resolved using blockchain technology. Respondents mentioned the following methods for resolving financial issues with blockchain technology. According to IP-1, it will help to manage cashflow activities, reduce non-payments, and payment issues in the supply chain. IP-2 stated that it will help to improve awareness of stakeholders and allow contractors to handle more projects at once. According to IP-3, it will enable cash flow automation, the removal of payment delays, transaction management, and the reduction 
of obtaining bonds and unnecessary bank charges. IP-4 also mentioned transparency, auditability, will help to resolve cash flow issues, and increased foreign investment. Furthermore, said that because all transactions are recorded in the ledger, it aids data management and decision-making. According to IP-5, IP-6, IP-7, and IP-8, blockchain technology can help to achieve trust, traceability, transparency, and accountability, which will help to reduce late payment issues, payment withholding, increase foreign investment, BOI activities, increase trust between the parties, and increase payment security.

Furthermore, experts mention that implementing a decentralised currency system will aid in the acquisition of blockchain features such as data encryption, immutability system, data distribution, data decentralisation, and tokenisation. Table 3 illustrates the causes that can be solved by blockchain technology in the Sri Lankan construction industry.

Table 3: Financial issues covered through blockchain technology

\begin{tabular}{|c|c|}
\hline Benefit of the blockchain & Effected financial issues \\
\hline \multirow[t]{2}{*}{ Faster transaction } & Reduce late payment issues \\
\hline & With smart contract reduce payment withholding \\
\hline \multirow[t]{3}{*}{$\begin{array}{l}\text { Removing third parties } \\
\text { from the transaction }\end{array}$} & $\begin{array}{l}\text { Reduce the involvement of too many parties in the } \\
\text { process of certification }\end{array}$ \\
\hline & Reduce obtaining loans \\
\hline & Remove the requirement of bonds and guarantees \\
\hline \multirow{5}{*}{$\begin{array}{l}\text { Trust, security, } \\
\text { transparency, and } \\
\text { responsibility of data and } \\
\text { transaction }\end{array}$} & Reduce issues in foreign investment \\
\hline & Reduce issues in BOI activities \\
\hline & Reduce lack of trust among stakeholders \\
\hline & Reduce non-payments \\
\hline & Reduce lack of security of the payments \\
\hline \multirow[t]{2}{*}{ Accountability } & Reduce cash flow issues \\
\hline & $\begin{array}{l}\text { Reduce issues when handles too many projects at } \\
\text { the same time }\end{array}$ \\
\hline \multirow[t]{2}{*}{ Traceability } & Reduce payment issues in the supply chain \\
\hline & Reduce issues in stakeholder's payments \\
\hline
\end{tabular}

\subsubsection{Difficulties in Implementing Blockchain Technology}

In the interviews, participants were asked to identify the challenges of blockchain technology when applied to the Sri Lankan construction industry. According to IP-1 and IP-2, the main impact will be legal challenges, a lack of IT knowledge, government enthusiasm, the cost of technology, and taxation issues. According to IP-3, our infrastructure is not yet ready, and the central bank is not yet providing any facilities. IP4 stated that the main issue will be adapting to the technology, as well as changing people's attitudes toward this technology. also mentioned reluctance to use, negative attitudes toward new technology, and scalability as major challenges. According to IP-6, the industry is not yet ready due to a lack of knowledge in this area, low investment, and the need to adopt blockchain technology as a whole industry rather than as an individual. According to IP-7, the development and adoption of the technology will necessitate a great deal of expertise, as well as changing people's minds about using it as a major challenge. IP-8 said that the main issue will be many people's reluctance to change; 
additionally, the construction industry lags far behind other industries. Also, mention that the construction industry lacks the capital to invest in these new technologies. Figure 4 depicts the difficulties associated with blockchain technology in the local context.

\begin{tabular}{|c|c|c|c|c|c|}
\hline \multicolumn{6}{|c|}{ Codes } \\
\hline$\odot$ & \multicolumn{2}{|c|}{ Name } & ' $\leftrightarrow$ & Files & References \\
\hline$\nabla 0$ & \multicolumn{2}{|r|}{ Challenges in adapting to blockchain technology } & & 7 & 7 \\
\hline & $\mathrm{O}$ & Adopting to the technology & & 1 & 1 \\
\hline & $\mathrm{O}$ & Changing people's mindset & & 4 & 4 \\
\hline & $\mathrm{O}$ & Cost of the technology & & 1 & 1 \\
\hline & $\mathrm{O}$ & Government enthusiasm & & 1 & 1 \\
\hline & $\mathrm{O}$ & Industry is not ready & & 3 & 3 \\
\hline & $\mathrm{O}$ & Lack of knowledge in the area & & 3 & 3 \\
\hline & $\mathrm{O}$ & Legal challenges & & 2 & 2 \\
\hline & 0 & Low investment & & 1 & 1 \\
\hline & 0 & Tax issues & & 2 & 2 \\
\hline
\end{tabular}

Figure 4: Difficulties in adopting blockchain technology

\subsubsection{Solutions to Difficulties Encountered when Implementing Blockchain Technology}

In the Sri Lankan context, there are several challenges to overcome. Legal issues, lack of knowledge in the blockchain, government enthusiasm, cost of the technology, tax issues, low investment, and changing people's minds about blockchain technology. Experts recommend several approaches to overcoming these obstacles. According to IP-1 and IP-6, new rules and regulations can help to mitigate some of the challenges such as legal issues, government enthusiasm, and tax issues. IP-2 suggests that acquiring knowledge and expertise from developed countries, as well as purchasing technology from them, will help to reduce challenges such as a lack of blockchain knowledge, the cost of technology, and low investment. IP-3 stated that allowing cryptocurrencies in the industry for both receiving and sending, creating a good platform for doing transactions, improving organisational digital infrastructure, and all parties involved in the project needing to be in the same network to work effectively will help to overcome challenges. According to IP-4 and IP-5, increased awareness and confidence will aid in overcoming social issues as well as low technological investment. IP-7 stated that general technological advancement, more blockchain research, public sector support, and private sector investment will help to reduce social issues, government enthusiasm, and low investment.

\section{DISCUSSION AND CONCLUSIONS}

Simply, blockchain technology is a technology that uses distributed ledger technology, whether for transactions, ownership transfers, to make an agreement between two parties and also many usages yet to be discovered. Blockchain technology provides unique options like faster transactions, digital transactions, accountability, traceability and increases trust, security, transparency, and responsibility. Hence, it aids to reduce late payment issues, payment withholding by using faster and digital transactions, removing intermedia parties from transactions, improve security in foreign or BOI payments by providing trust and security of the payment, accountability, traceability help to manage 
cash flow activities, trust and transparency will help remove providing bonds and guarantees.

When applied to the local context, blockchain technology presents numerous challenges. Some of them were legal issues, a lack of knowledge in the area, government enthusiasm, the cost of technology, tax issues, low investment, and changing people's minds. The government rules and regulations can help to mitigate legal issues, tax issues, and government enthusiasm. The government can make rules and regulations for the blockchain system and allow transactions using cryptocurrencies. Buying a blockchain system from a developer will help to mitigate the lack of knowledge and cost of the technology. Low investment and changing public opinions can be managed by using pilot projects with blockchain technology. This will help to improve investment in blockchain technology. As a result, the research findings suggest that blockchain technology could help to reduce several financial issues while also allowing the Sri Lankan construction industry to digitalise its future.

\section{REFERENCES}

Abdul-Rahman, H., Berawi, M.A., Berawi, A.R., Mohamed, O., Othman, M. and Yahya, I.A., 2006. Delay mitigation in the Malaysian construction industry. Journal of Construction Engineering and Management, 132(2), pp. 125-133.

Abdul-Rahman, H., Wang, C., Takim, R. and Wong, S., 2011. Project schedule influenced by financial issues: Evidence in construction industry. Academic Journals, 6(1), pp. 205-212.

Ahmed, Y.B. and Ahmed, A., 2016. Financial risks contributing to delay of oil and gas projects in Egypt. International Journal of Accounting, Finance and Risk Management, 1(1), pp. 19-24.

Al-Momani, A.H., 2000. Construction delay: A quantitative analysis. International Journal of Project Management, 18(1), pp. 51-59.

Azis, A.A.A., Memon, A.H., Rahman, I.A., Nagapan, S. and Latif, Q.B.A.I., 2012. Challenges faced by construction industry in accomplishing sustainablity goals. 2012 IEEE Symposium on Business, Engineering and Industrial Applications, Bandung 23-26 September 2012, pp. 628-633.

De Silva, N., 2020. Challenges faced by the construction industry in Sri Lanka: Perspective of clients and contractors. pp. 158-169.

Fulford, R. and Standing, C., 2014. Construction industry productivity and the potential for collaborative practice. International Journal of Project Management, 32(2), pp. 315-326.

Ghaffari, F., Bertin, E., Hatin, J. and Crespi, N., 2020. Authentication and access control based on distributed ledger technology. 2020 2nd Conference on Blockchain Research \& Applications for Innovative Networks and Services (BRAINS), Paris 28-30 September 2020, pp. 79-86.

Ghosh, A., Chakraborty, D. and Law, A., 2018. Artificial intelligence in internet of things. CAAI Transactions on Intelligence Technology, 3(4), pp. 208-218.

Gundes, S., Atakul, N. and Buyukyoran, F., 2019. Financial issues in construction companies: bibliometric analysis and trends. Canadian Journal of Civil Engineering, 46(4), pp. 329-337.

Gururaj, H.L., Manoj, A.A., Kumar, A.A., Holla, A.M., Nagarajath, S.M., and Kumar, V.R., 2020 a. Blockchain. In: Cryptocurrencies and blockchain technology applications, pp. 1-24.

Gururaj, H.L., Manoj, A.A., Kumar, A.A., Nagarajath, S.M., and Kumar, V.R., 2020b. Adoption of pets in distributed network using blockchain technology. International Journal of Blockchains and Cryptocurrencies, 1(2), p. 107.

Harris, F. and McCaffer, R., 2003. Modern construction management. $5^{\text {th }}$ ed. Oxford, UK: Blackwell Science.

Hellwig, D., Karlic, G. and Huchzermeier, A., 2020a. Blockchain cryptography part 1. Build Your Own Blockchain, pp. 125-148.

Hellwig, D., Karlic, G. and Huchzermeier, A., 2020b. Cryptocurrencies. Build Your Own Blockchain, pp. 29-51.

Hewavitharana, T., Nanayakkara, S. and Perera, S., 2019. Blockchain as a project management platform. In: Sandanayake, Y.G., Gunatilake, S. and Waidyasekara, A. (eds). In Proceedings of the $8^{\text {th }}$ World 
Construction Symposium, Colombo, Sri Lanka, 8-10 November 2019, pp. 137-146. Available from: https://2019.ciobwcs.com/downloads/papers/WCS2019_14.pdf

Holotescu, C., 2018. Understanding blockchain opportunities and challenges. The $14^{\text {th }}$ International Scientific Conference eLearning and Software for Education, Bucharest 19-20 April 2018, pp. 275-283.

Igwe, U.S., Mohamed, S.F. and Azwarie, M.B.M.D., 2020. Recent technologies in construction: A novel search for total cost management of construction projects. IOP Conference Series: Materials Science and Engineering, 884(1), pp.1-20.

Ioini, N.E. and Pahl, C., 2018a. Trustworthy orchestration of container based edge computing using permissioned blockchain. 2018 Fifth International Conference on Internet of Things: Systems, Management and Security, Valencia 15-18 October 2018. Institute of Electrical and Electronics Engineers, pp. 147-154.

Ioini, N.E. and Pahl, C., 2018b. A review of distributed ledger technologies. OTM Confederated International Conferences on the Move to Meaningful Internet Systems, pp. 277-288.

Kubba, S., 2010. Green construction project management and cost oversight. Amsterdam: Elsevier/ Architectural Press.

Kuhn, R., Yaga, D. and Voas, J., 2019. Rethinking distributed ledger technology. Computer, 52(2), pp. 6872.

Lall, M.M., 2020. Blockchain. The Blackwell Encyclopedia of Sociology, pp. 1-6.

McKinsey and Company, 2015. The construction productivity imperative. [Online] Available from: https://www.mckinsey.it/idee/the-construction-productivity-imperative_[Accessed 20 July 2015].

Mehta, V., 2018. What is the importance of financial management?. [Online] Available from: https://www.lsbf.org.uk/blog/news/importance-of-financial-management/117410 [Accessed 7 September 2018].

Nakamoto, S., 2009. Bitcoin: A peer-to-peer electronic cash system. [Online] Available from: https://bitcoin.org/bitcoin.pdf [Accessed 31 October 2009].

Nordgren, A. and Weckstrom, E., 2019. Blockchain in the fields of finance and accounting: a disruptive technology or an overhyped phenomenon?. ACRN Oxford Journal of Finance and Risk Perspectives, pp. 47-58.

Panda, S.K., Elngar, A., Balas, V.E. and Kayed, M., 2020. Bitcoin and blockchain: History and current applications. Boca Raton: CRC Press, Francis and Taylor.

Persis, V., 2020. Blockchain-UN. University News, 58(14), pp. 9-11.

Ramachandra, T. and Rotimi, J. O., 2015. The nature of payment problems in the New Zealand construction industry. Construction Economics and Building, 15(1), pp. 43-55.

Sunyaev, A., 2020. Distributed ledger technology. Internet Computing, pp. 265-299.

Turk, Z. and Klinc, R., 2017. Potentials of blockchain technology for construction management. Creative Construction Conference, Primosten, Croatia, 19-22 June 2017, Volume 196, pp. 638-645.

Watson, S. and Hjelte, H., 2018. What is blockchain. Modus Asia edition, pp. 27-29.

Xu, L., Markus, I.,I,S. and Nayab, N., 2019. Blockchain-based access control for enterprise blockchain applications. International Journal of Network Management 30(5), pp. 1-13.

Yoo, S., 2017. Blockchain based financial case analysis and its implications. Asia Pacific Journal of Innovation and Entrepreneurship, 11(3), pp. 312-321.

Zheng, Z., Xie, S., Dai, H., Dai, H., Chen, X., and Wang, H., 2017. An overview of blockchain technology: architecture, consensus, and future trends. 2017 IEEE International Congress on Big Data (BigData Congress), pp. 557-564. 